\title{
\begin{tabular}{l|l} 
Mibraries & DSpace@MIT
\end{tabular}
}

\author{
MIT Open Access Articles
}

\section{An Investigation on the Inconsistency of Consumer Preferences for Product Appearance: A Case Study of Residential Solar Panels}

The MIT Faculty has made this article openly available. Please share how this access benefits you. Your story matters.

Citation: Bao, Qifang, Sami El Ferik, Mian Mobeen Shaukat, and Maria C. Yang. “An Investigation on the Inconsistency of Consumer Preferences for Product Appearance: A Case Study of Residential Solar Panels." Volume 7: 2nd Biennial International Conference on Dynamics for Design; 26th International Conference on Design Theory and Methodology (August 17, 2014).

As Published: http://dx.doi.org/10.1115/DETC2014-34799

Publisher: ASME International

Persistent URL: http://hdl.handle.net/1721.1/120028

Version: Final published version: final published article, as it appeared in a journal, conference proceedings, or other formally published context

Terms of Use: Article is made available in accordance with the publisher's policy and may be subject to US copyright law. Please refer to the publisher's site for terms of use. 


\section{AN INVESTIGATION ON THE INCONSISTENCY OF CONSUMER PREFERENCES FOR PRODUCT APPEARANCE: A CASE STUDY OF RESIDENTIAL SOLAR PANELS}

\author{
Qifang Bao \\ Department of Mechanical Engineering \\ Massachusetts Institute of Technology \\ Cambridge, MA \\ Mian Mobeen Shaukat \\ Department of Mechanical Engineering \\ King Fahd University of Petroleum and Minerals \\ Dhahran Saudi Arabia
}

\author{
Sami El Ferik \\ Department of System Engineering \\ King Fahd University of Petroleum and Minerals \\ Dhahran Saudi Arabia \\ Maria C. Yang \\ Department of Mechanical Engineering and \\ Engineering Systems Division \\ Massachusetts Institute of Technology \\ Cambridge, MA
}

\begin{abstract}
The importance of the appearance of consumer products is widely understood. This paper considers an evaluation of the appearance of a technology-oriented product, the residential solar panel, from the perspective of individuals. This study uses a quantitative approach, visual conjoint analysis, to determine preferences for product appearance of solar panels, and further explores how presenting a solar panel in its context of use can influence the consistency of consumer preferences. Approximately 200 survey respondents were shown two kinds of images of solar panels, one of a standalone panel and the other of a panel installed on a roof. Results show a significant shift of preferences when first showing the non-contextualized image and then showing the contextualized image. Such preference inconsistency provides insights with which to inform the process of user-needs revealing.
\end{abstract}

\section{INTRODUCTION}

Understanding users' needs is critical to the formulation of comprehensive design requirements and the future success of a product. Users' needs can touch on many aspects of a product, including price, functional performance, sustainability, brand, as well as product appearance. The aesthetic value of a product can be defined as the pleasure derived from seeing the product, without consideration of utility [1]. For some technology-push products that are developed around technological innovation rather than userneeds or market-needs [2], appearance is usually considered after performance or price. However, as a product rises on the S-curve of technology diffusion, that is, the technology becomes more mature and more familiar to the consumer, product appearance may play a larger role in influencing customer's buying decisions.

In this study, we examine the appearance preferences for residential solar panels. Much research has been conducted on technologies to improve engineering performance, particularly efficiency and manufacturability of the panels. Typically, elements such as panel color, size, and frame style are byproducts of engineering performance considerations. Darker solar panels are generally more efficient, while manufacturing methods and ease of installation issues govern the size and shape of a panel. However, a solar panel's appearance can dramatically change the visual appeal of a home and thus influence whether a homeowner chooses to invest in a system and further adoption of the technology.

To obtain meaningful and accurate information from users, conjoint analysis has been widely used as a costefficient tool to capture preference of products. Traditional conjoint has been proved to be successful in capturing descriptive features [3]. Visual conjoint analysis allows users to express preferences for visual features of a product such as form, size and color [4]. Studies have demonstrated the ability to accurately capture consumer preferences of this method by 
simplifying symbolic graphs to represent the appearance and identity of a product, such as using Bezier curves to represent the outline of an automobile [4].

Many strategies exist for obtaining and estimating consumer preferences, from qualitative ethnographic approaches to quantitative computational strategies. However, inconsistency is an innate feature of individual preference due to the case-by-case preference construction process [5], and it is often difficult to make the "best" decision on product design [6]. This is also true for preferences for product appearance. In some sense, preferences for product appearance can be more easily biased, since it deals with a primarily visceral response [7]. One experiment has shown that opinions for products are inconsistent across forms, between computer sketch / FSV (3D file system visualizer) silhouette and realistic rendering, though inferences are consistent [8]. Understanding these inconsistencies will provide product designers and engineers insights on the decision making process of customers [5], thus helping them better understand consumer preferences for product appearance.

In addition to assessing the appearance preferences for a solar panel, this study examines how sensitive a customer might be to the particular way a panel is presented. As one might expect, solar panel datasheets generally showcase a panel on a blank background, without any visual context. However, residential solar panels are installed on roofs of widely varying color, shape, materials and slope. And the homeowners may not see how a panel looks on their own roof until after it is installed.

This study poses three questions about preferences for a solar panel's product appearance:

1. Are preferences for a solar panel's appearance the same when a panel is presented in images with/without a context?

2. Are preferences consistent when the attributes of product appearance are evaluated all together (conjoint analysis) compared with evaluated separately (directly stated)?

3. If the preferences for product appearance are not consistent, then what are the main factors that influence preferences?

Visual conjoint analysis is used to capture consumer preferences for solar panels with various product appearance attributes, along with a stated preference survey.

\section{PREVIOUS WORK}

\section{Product appearance}

Human interfaces and industrial design are often regarded as key marketing elements of a product [9]. The appearance of a product is partly determined by the functions it performs, and is partly designed to convey performance and emotional information to users [10]. Thus the appearance plays an important role in defining the product-person relationship [11].
A core practice of the field of industrial design is product styling, developing forms for a product that are both appropriate for the design and attractive. At the intersection of industrial design and engineering, some research has been conducted on product appearance for cases such as vehicles and mobile phones $[12,13]$. Other research has been conducted on how style and fidelity of preliminary design representations can influence users' response to product concepts [14], and has found that users believe realistic, finished drawings to be more appealing. User interaction designers have also considered the topic for software design, and found that designs that are perceived as more attractive are considered better, whether or not they actually are more effective [15].

The appearance of residential solar panels, which are traditionally considered engineering performance driven products rather than styling driven, has not received as much research attention. In a survey of 200 solar panel installers, Chen, et al. found that installers were generally the stakeholders who make the primary decision on what solar panels will be made available to the homeowners. The survey found that the appearance of the panels was a high priority attribute among installers [16]. In the same study, installers were presented images on a blank (no context) background of four different kinds of panels, varying the color of frame and the surface texture. Results of the survey suggested that, an "even surface with dark-colored frame" is the most preferable solar panel style.

\section{Conjoint Analysis}

Conjoint analysis is a method used to address the additive effect of a set of individual variables on consumer preference. It is widely used in market research to determine how people value different features that make up an individual product or service [17]. When using conjoint analysis, several attributes of a product are chosen, each of which can be varied in discrete levels. A controlled set of potential products is created by experimental design, each of which contains a combination of the attributes [18]. Full-factorial design is a choice for product profile generation when the number of product feature is limited. However, when the number of product features is large, fractional-factorial experimental designs can be used to capture consumer preferences, substantially reducing the number of questions [19].

After the set is prepared, users are asked to rate, rank or choose among the product profiles. By their rating, ranking or choices, utility models can be built and predictions can be made about the users' future preferences. Choice based conjoint presents several products with different combinations of attributes to users and asks them to choose the one he/she likes the most [20]. Compared to the ranking or rating conjoint method, choice based conjoint has the advantage of more realistically mimicking customers' purchasing behavior.

Conjoint analysis has been traditionally used on descriptive features of products. Visual conjoint expands the use of the method by allowing judgment on a product's appearance. In Kelly, et al.'s work, two attributes were varied 
to generate different shape of a cola bottle [21]. In Swamy, et al.'s work, four-control-point Bezier curves were defined to generate the shape of a vehicle headlight [22]. In Orsborn, et al.'s study, seven attributes were determined to fully describe the outline of an SUV [4]. These 2D visual representations are further combined with functional attributes of products to understand consumer preference from other perspectives such as perceived environmental friendliness or the emotion and reasoning behind the choices [23,24].

Experimental conjoint methodology was proposed by Tovares, et al. [3]. Virtual reality was combined with conjoint analysis to create a vivid use environment. This method allowed users to judge not only how a product looked, but also how it would feel to use as a product.

\section{Research gap}

Visual conjoint analysis is a relatively new approach for studying product appearance. Only a limited variety of products have been studied using this method. In addition, the influence of the style of visual representations in users' response has not been studied yet using visual conjoint. The work presented in this paper tries to fill the gap by applying visual conjoint analysis to solar panels. In addition, it explores the potential preference inconsistencies caused by different ways of presenting a product.

\section{METHODOLOGY}

This study involves presenting users with an online survey of images of solar panels with varying product attributes. The details of the creation of the survey and images, survey administration, and data analysis follow below.

\section{Identification of attributes}

Datasheets of 265 different models of residential solar panels from 37 different brands were collected as part of a previous study [16]. These panel types were successfully sold on the open California market from 2007-11, and were drawn from the California Solar Initiative's database [25].

In this current study, analysis of the product images included in the datasheets identified four key attributes of a panels' appearance: 1) color of the solar cells 2) shape of the corners of the solar cell 3) pattern of the front contact wires of the solar cells, and 4) the style of frame. In the experiment, each attribute was varied on 3 4 different levels, which can be found in Table 1.
In fact, the attributes identified are not only related to the appearance of solar panels, but are also connected with engineering criteria such as performance and price. For example, the color of the panel is directly determined by the solar cell coding material. The shape of a solar cell is related to the usage rate of silicon wafer, the fabrication materials, and the power generation efficiency per area of the solar panel. For the sake of simplicity, here we do not consider the variation of any criteria except those relating to aesthetics, holding all other attributes constant.

\section{Survey Design}

A survey was designed and distributed through Amazon Mechanical Turk, a crowdsourcing Internet marketplace where Human Intelligence Tasks are posted and completed by MTurk Workers. The respondents of the survey were confined to adults in the US. Informed consents from the participants were obtained at the beginning of the survey. Each participant was compensated with $\$ 1.50$, approximately $\$ 6.00$ per hour.

A pilot study was conducted with 8 participants and their feedback on overall content, wording, and survey length were considered in refining the survey.

The six parts of the survey (Figure 1) were designed to take an average time of $15 \mathrm{~min}$ to complete. The sequence of the six parts was designed to reduce possible bias of preference as the respondents progressed from one section to the next.

\section{Creation of images}

Two different kinds of images of solar panels were created specifically for this survey:

$>$ Non-contextualized: Images of solar panels from a front view on a blank white background.

> Contextualized: Images of solar panels installed on houses with different style and color of roofs. The panels may be shown at an angle, depending on the roof style.

Images were created using Adobe Photoshop, and all levels of the attributes were controlled to minimize possible bias introduced by factors such as different image fidelity. For the contextualized images, the combination of panels and roofs were chosen randomly, without specific match of styles between the two. Figure 2 shows examples of the two kinds of images.

Table 1: Levels of attributes influencing the appearance of solar panels

\begin{tabular}{|c|c|c|c|c|c|}
\hline Attributes & Num. of Levels & Level 1 & Level 2 & Level 3 & Level 4 \\
\hline Color & 4 & Black & Blue & Red & Green \\
\hline Shape & 3 & $\begin{array}{c}\text { Big rounded } \\
\text { corner cell }\end{array}$ & $\begin{array}{c}\text { Small rounded } \\
\text { corner cell }\end{array}$ & Square cell & \\
\hline Pattern & 3 & No pattern & $\begin{array}{c}\text { Two main contact } \\
\text { wires }\end{array}$ & $\begin{array}{c}\text { Three main } \\
\text { contact wires }\end{array}$ & \\
\hline Frame & 3 & Silver frame & Black frame & No frame & \\
\hline
\end{tabular}


Part I A general introduction of the study and an introduction of the four attributes of solar panels.

Part II A choice base conjoint questionnaire containing 32 questions asking the participant to choose the more preferred solar panel from two options. Respondents are asked to use only the panel's appearance as the only criteria to consider when comparing the two panels. Noncontextualized images are used.

Part III A direct statement survey asking participants to choose their most preferred level for each of the four attributes.

Part IV A choice based conjoint questionnaire with five questions asking the participant to choose the more preferred solar panel between two options. Contextualized images are used.

Part V A solar panel design questionnaire. Five images of different houses are presented. Participants are asked to select their most preferred combination of the solar panels on the roof of the houses.

Part VI A questionnaire asking basic demographic information such as gender, age, geographical location, type of residence.

\section{Figure 1: Structure of the survey}
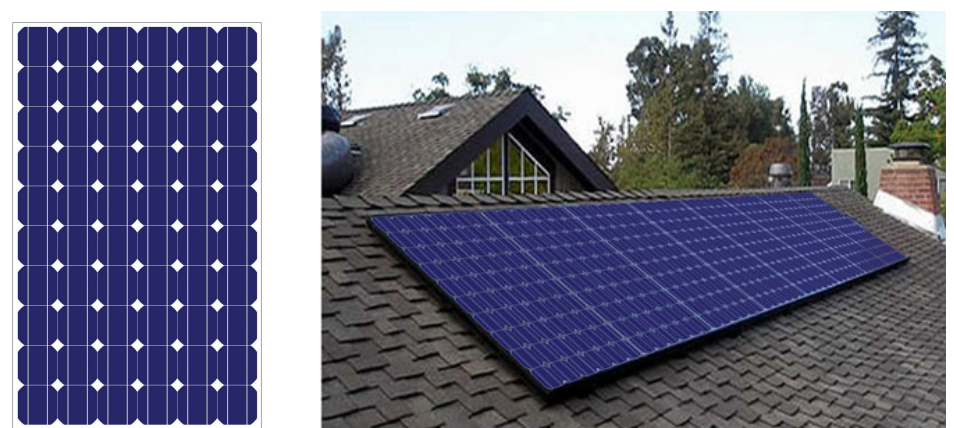

Non-contextualized

Contextualized

Figure 2: Examples of the created images. Panels in the two images have the same combination of attributes: blue, big rounded corner cell, two main contact wires and no frame.

\section{Data Analysis methods}

The conjoint analysis data was analyzed using the Bradley-Terri-Luce (BTL) equation [4], which is often applied to pairwise comparison data:

$$
P\left(x_{i j}\right)=\frac{w_{i j C}}{w_{i j}}
$$

Here $\mathrm{x}_{\mathrm{ij}}$ is the $j^{\text {th }}$ level of attribute $i$. The probability attribute $\mathrm{x}_{\mathrm{ij}}$ will be chosen, $P\left(x_{i j}\right)$, is given by dividing $w_{i j c}$, the number of times attribute level $\mathrm{x}_{\mathrm{ij}}$ was selected in the conjoint survey, by $w_{i j}$, the total number of times attribute level $\mathrm{x}_{\mathrm{ij}}$ was presented in survey.

$$
\hat{u}_{i}=f_{i}\left(x_{i j}\right)=P\left(x_{i j}\right)
$$

The part-worth utility of each attribute is estimated by the chosen probability. In eq. $2, \hat{u}_{i}$ is the estimation of part-worth utility of attribute $i . f_{i}$ is the mapping from level of attributes to the part-worth utility. The level with the highest utility was noted as the most preferred level of the attribute.

The total part-worth utility of a product is given by the sum of that of each attribute:

$$
U=\sum_{i=1}^{m} u_{i}
$$

A larger part-worth utility represents a higher preference. When using the model to predict future choice, the product with the higher estimated part-worth utility will be chosen.

The first 27 questions in survey part II are used to create the preference model. The remaining 5 questions in part II are the first holdout set of questions used to cross validate the prediction accuracy of the model. The 5 questions of the contextualized images in part IV are the second cross validating set. These two question sets correspond with 5 randomly picked questions in the 27-question set, which means that the extra $5+5$ questions have the same solar panel pairs as 5 previously asked questions.

This repetition of questions should not be obvious to respondents if the total number of questions is sufficiently large. Thus there is only limited risk that participants memorize their answers and make the same choice within same solar panel pairs intentionally. We can assume that every time a participant answers a question, whether he/she has seen it before or not, he/she will make the choice only based on their current judgment of the product appearance, not their memory of answers to previous questions and an obligation to answer consistently.

Figure 3 shows a flow chart that explains the process of model creation, prediction, and comparisons of preference consistency.

As can be seen in the flow chart, the 27 questions with non-contextualized images are used to create the preference model. Then the model is used to predict the customer's preferences for the extra 5 questions with non-contextualized images, as well as the 5 questions with contextualized images. The prediction results are compared to the real choices participants made for the $5+5$ questions to show the prediction accuracy of the model and to evaluate the preference consistency.

In addition, the answers to the extra 5 questions with noncontextualized images and the answers to the 5 questions with contextualized images are compared directly to their corresponding questions in the 27-question set. This comparison also reveals information about participants' preference inconsistency.

Later the most preferred levels revealed by conjoint analysis are compared to the responses to part III of the survey, where participants give answers to their most preferred level for each of the four attributes directly. The most preferred levels are also compared to the design outcome of the survey part V. 


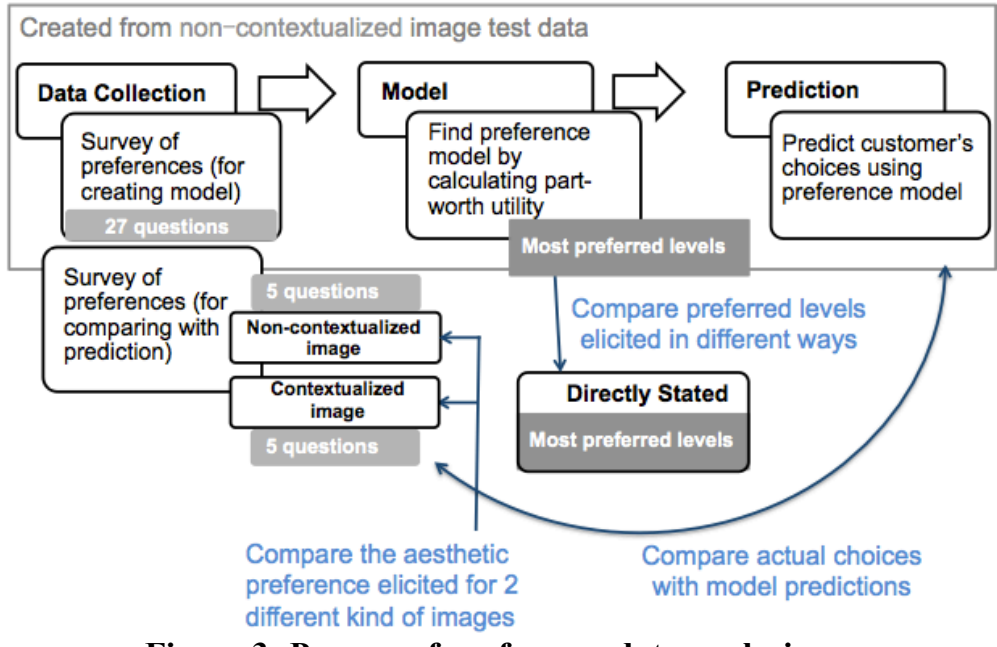

Figure 3: Process of preference data analysis

\section{RESULTS}

\section{Participants}

A total of 227 participants responded to the survey. Two criteria were used to screen the data: i) Responding time. Surveys completed in too little time (less than $8 \mathrm{~min}$ ) were considered to be low quality, and therefore were rejected; ii) 'Correct answer'. A simple objective question was set inside the survey, and those that failed to answer it were considered low quality thus were rejected. 33 of the responses were rejected, leaving 194 responses to the survey being used in the final data analysis.

Among the valid data, the demographic information of the participants is as the following: 110 male, 84 female, age ranging from 20 to more than 60, all living in United States.

\section{Individual preference model}

By calculating the part-worth utility of each attribute level, level, the preference models were built for each participant.
Figure 4 is an example from one participant. The preference models are described by blue dots representing equation (1). The most preferred levels are marked by red bars. Figure 5 is a summary of the preference models.

Later, the models are used to predict participants' choices on other questions using equation (2).

\section{Using the preference model in}

Figure 4 as an example, when comparing i) A black panel with big rounded corner, no pattern cell, and a silver frame with ii) A blue panel with small rounded corner, two main contact wires cell with a black frame, the estimated part-worth utility of the two panels are given as below:

$$
\begin{aligned}
& \widehat{U}_{1}=\hat{u}_{\text {Color }}+\hat{u}_{\text {Shape }}+\hat{u}_{\text {Pattern }}+\hat{u}_{\text {Frame }} \\
& \quad=0.38+0.44+0.48+0.41=1.71 \\
& \widehat{U}_{2}=\hat{u}_{\text {Color }}+\hat{u}_{\text {Shape }}+\hat{u}_{\text {Pattern }}+\hat{u}_{\text {Frame }} \\
& \quad=0.13+0.37+0.15+0.33=0.98
\end{aligned}
$$

Since $\widehat{U}_{1}>\widehat{U}_{2}$, the model predicts that this participant will prefer the first panel over the second one. If he/she does choose panel ii) over panel i), we claim that the model makes the "right" prediction.

\section{Preference inconsistency between images of different style}

The last 5 questions in Part II (with non-contextualized images) and the 5 questions in Part VI (with contextualized images) of the survey are used for checking the accuracy of the model.

Prediction accuracy is the number of "right" predictions made over the number of total predictions made by a preference model. Every participant has his/her own preference model and his/her own prediction accuracy value for both non-contextualized image questions and contextualized image questions.

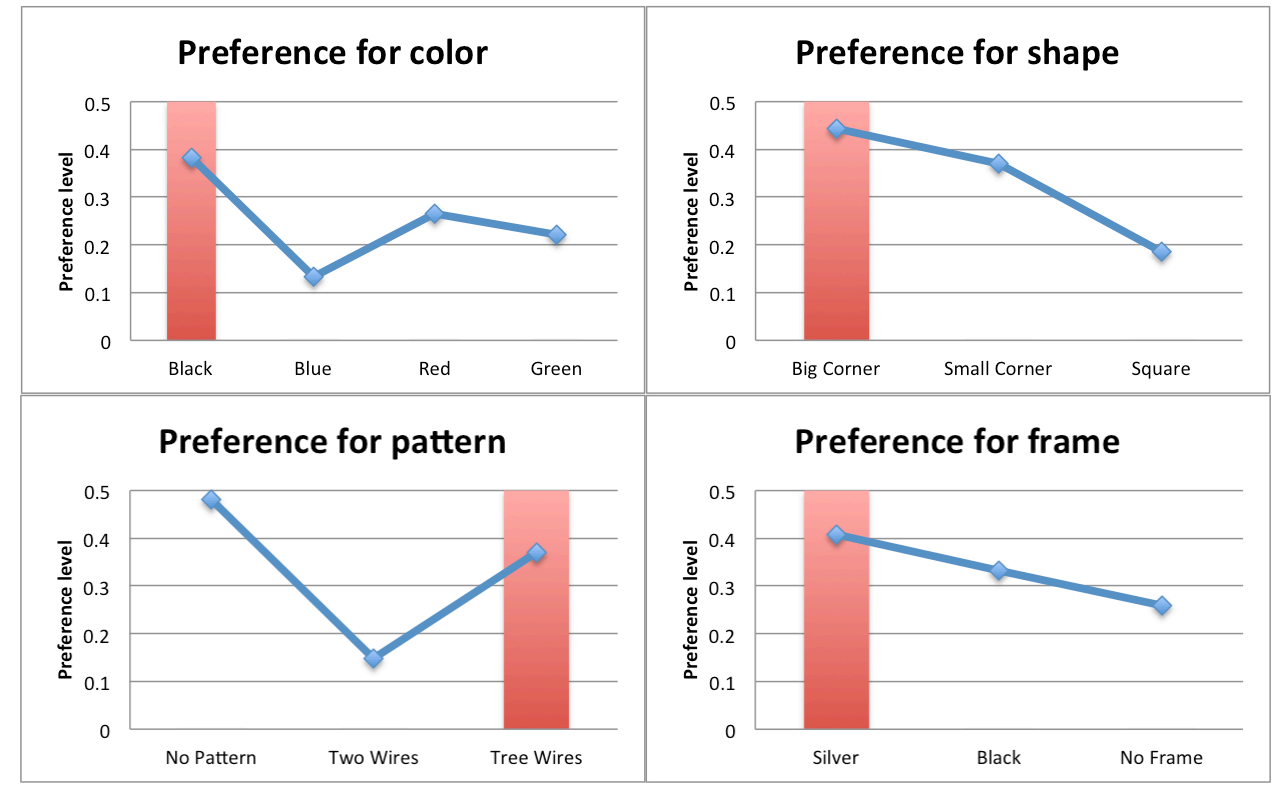

Figure 4: Preference model from one participant 


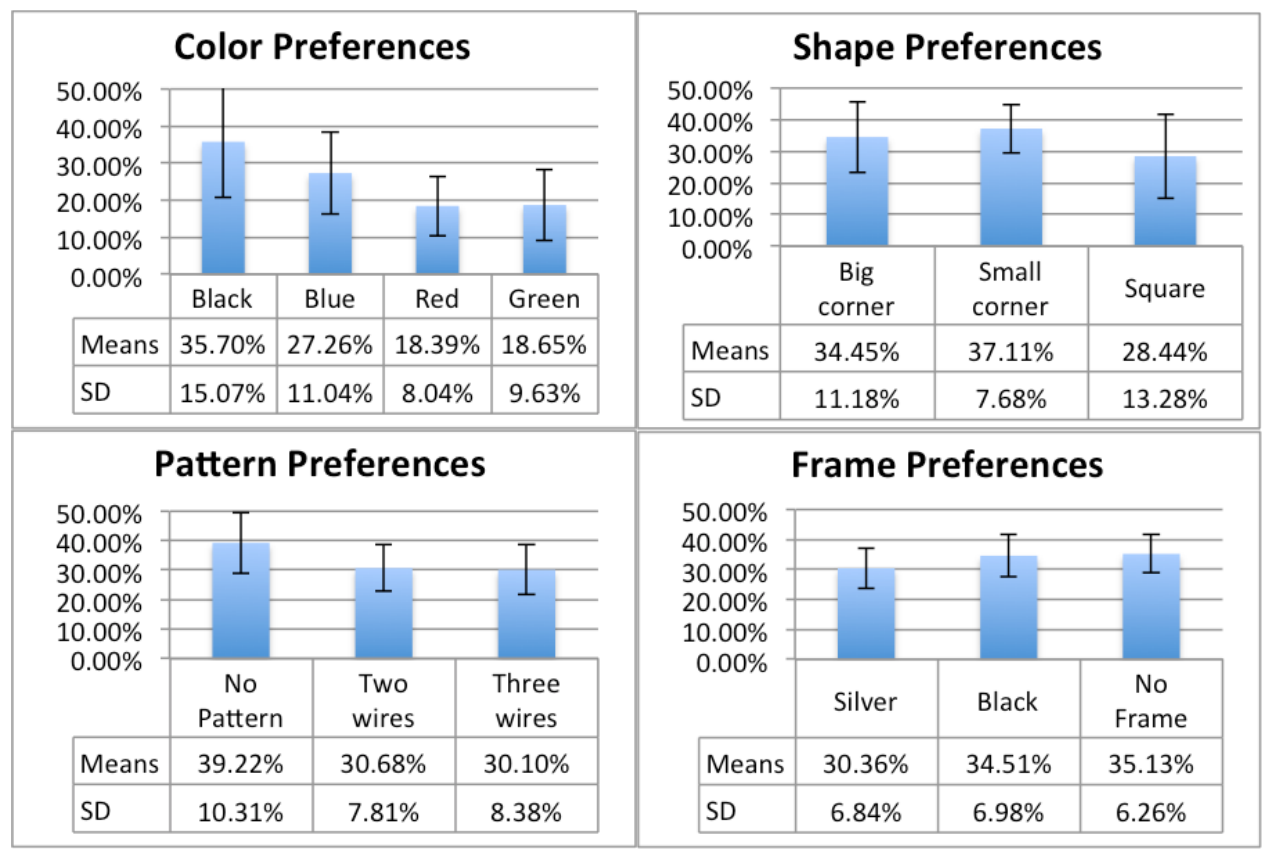

Figure 5: Summary of preference model

Table 2 is a summary of 194 individual prediction accuracies. An average of $70.8 \%$ prediction accuracy of noncontextualized images suggests a relatively good prediction ability of the model when the image style doesn't change (note that the preference models were built based on participants' answers to the questions with non-contextualized images). However when the style of the images changes to contextualized image, the models does not work as well any more.

The small $p$-value for one-way ANOVA indicates that there is a significant difference between the prediction accuracy for questions with different styles of images. The prediction accuracy for contextualized images is much lower than that for non-contextualized image questions.

Table 2: Prediction accuracy for non-contextualized images and for contextualized images

\begin{tabular}{|c|c|c|c|}
\hline & Average & St Dev. & ANOVA \\
\hline $\begin{array}{c}\text { Non-contextualized } \\
\text { images }\end{array}$ & $70.8 \%$ & $22.3 \%$ & \multirow{2}{*}{$\begin{array}{c}\mathrm{F}=57.44, \\
\mathrm{p}=2.61 \times 10^{-13}\end{array}$} \\
\hline $\begin{array}{c}\text { Contextualized } \\
\text { images }\end{array}$ & $53.0 \%$ & $24.0 \%$ & \\
\hline
\end{tabular}

For some people, their own preference models predict contextualized image questions more accurately than predict contextualized image problems for them. For some people, it is the opposite. For the others, their preference models predict both kinds of questions with same accuracy. Table 3 is a summary of the number of participants in these three categories. The results show that, more than half of the participants have higher prediction accuracy for noncontextualized image questions.
Table 3: Prediction accuracy comparison

\begin{tabular}{|c|c|c|}
\hline $\begin{array}{c}\text { Non- } \\
\text { contextualized } \\
\text { Contextualized }\end{array}$ & $\begin{array}{c}\text { Non- } \\
\text { contextualized } \\
\text { = Contextualized }\end{array}$ & $\begin{array}{c}\text { Non- } \\
\text { contextualized } \\
\text { <Contextualized }\end{array}$ \\
\hline 119 & 53 & 22 \\
\hline
\end{tabular}

In Table 4, the answers for the five non-contextualized image questions and the five contextualized image questions are compared directly to his/her previous answers to the corresponding questions.

Table 4: Preference matching rate

\begin{tabular}{|c|c|c|c|}
\hline & Average & St Dev. & ANOVA \\
\hline $\begin{array}{c}\text { Non-contextualized } \\
\text { images }\end{array}$ & $83.6 \%$ & $18.8 \%$ & \multirow{2}{*}{$\begin{array}{c}\mathrm{F}=80.39 \\
\mathrm{p}=1.34 \times 10^{-17}\end{array}$} \\
\hline $\begin{array}{c}\text { Contextualized } \\
\text { images }\end{array}$ & $64.4 \%$ & $23.2 \%$ & \\
\hline
\end{tabular}

The results show the inconsistency of preference. When respondents answered a question the second time with the same style of image, there was $83 \%$ chance they would state the same preferences that they did before. This random inconsistency has been observed before and the reason of the inconsistency was concluded as "stochastic choice" [26].

However, when respondents answered a question the second time in response to a different style of images (the contextualized images), only $64 \%$ chance they would still prefer the same solar panel. The small p-value of ANOVA indicates that the difference between the matching rates is significant. Thus the inconsistency of preference caused by changing image style is not random, but systematic. 


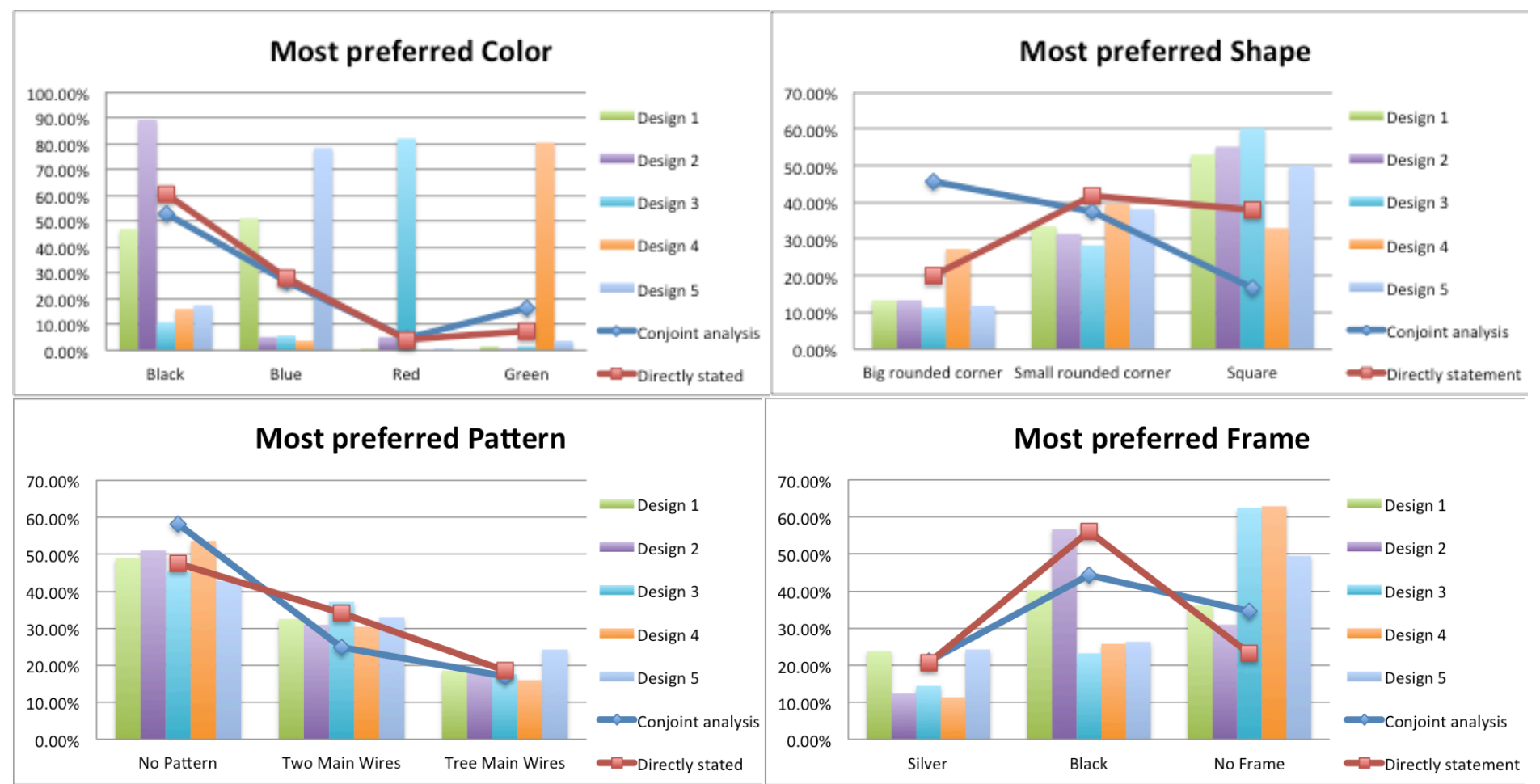

Figure 6: Summary of most preferred level of attributes

These together show a discrepancy of users' response when first using non-contextualized images and then using contextualized images in the visual conjoint. In other words, when comparing images of non-contextualized panels, a respondent might prefer a green frameless panel to a black silver-frame, for example. However, when comparing the same two panels presented in the context of a roof, the respondent is very likely to change the preference and prefer the latter to the former, providing the visual context is able to change the respondents' preference.

\section{Customized Design of solar panel}

Figure 6 is a summary of the answers to the five customized design questions. The most preferred levels of attributes are also presented in the graph as a reference. It can be seen that people's choices for the most preferred level of each attribute changes under different circumstances.

As for shape, Square is the most preferred in four design questions out of five and Big Rounded Corner is always the least preferred. These are different from either conjoint analysis or directly stated answer. The reason for the differences could be that the shape of the tiles on the roof influences people's preference for the shape of the cells on the panel.

For Pattern, "No Pattern" is the most preferred in all the five design questions, suggesting that a majority of the respondents find an even surface of the solar panels more attractive than patterned surface of the panels.

For Frame, "No Frame" is the most preferred for three design questions and "Black Frame" is the most preferred for the other two design questions. It seems that when the roof of the house has a dark color (gray), customers prefer "Black Frame" the most, and when the roof has a light color (red, green or blue), "No Frame" is considered to be the best match. "Silver Frame" is always the least preferred one.

Preferences for color changed the most under

different design situations. The color of the roofs in the images provided is likely the main cause for the preference change as can be seen in

Table 5. It was found that respondents tend to choose the color of the solar panel to match the roof - blue panels for blue roof, red panels for red roofs, etc. In addition, black is always a second preferred choice if not the first.

Table 5: Color of the roof and first two preferred color in five design questions

\begin{tabular}{|c|c|c|c|c|c|}
\hline & Design 1 & Design 2 & Design 3 & Design 4 & Design 5 \\
\hline Color of the roof & $\begin{array}{c}\text { Grey (with } \\
\text { blue eaves) }\end{array}$ & $\begin{array}{c}\text { Grey (with } \\
\text { white eaves) }\end{array}$ & Red & Green & Blue \\
\hline First preferred color & Blue & Black & Red & Green & Blue \\
\hline Second preferred color & Black & Blue/Red & Black & Black & Black \\
\hline
\end{tabular}




\section{Changing of 'Most Preferred' attribute from conjoint revealed result to directly stated result}

In Figure 6 the most preferred attributes revealed by conjoint analysis seem to be matching with the directly stated most preferred attributes pretty well. However, looking into details we can see that there is a high changing rate of the most preferred attributes.

Table 6 is a summary of the changes of most preferred attributes. The digit in row_X colum_Y represents the number of people whose most preferred attribute revealed by conjoint is $\mathrm{X}$, and stated directly is $\mathrm{Y}$. The bolded digits represent the number of people, of whom the most preferred attributes are consistent. Digits in gray cells represent the number of people whose most preferred attributes changed.

We can see that the most preferred Color revealed in the two ways generally consistent with each other. For Pattern and Frame however, though the summations of the most preferred attribute on each single level are similar, the inconsistency is high. Take Pattern as an example: there are 36 people whose conjoint revealed favorite pattern is 'No pattern'. However their directly stated favorite pattern is 'Two main wires'. It is almost $1 / 3$ of the population whose conjoint revealed favorite pattern is 'No pattern'.

\section{DISCUSSION}

The results of this study show the existence of inconsistency when revealing appearance preference for solar panel from consumers. To answer the questions we asked in the beginning of the paper:

1. Are preferences for a solar panel's appearance the same when a panel is presented in images with/without a context?

No. When the style of product representation of the solar panel changes from a non-contextualized image with a blank background to contextualized image within realistic context, the appearance preference shifts. We can see this from the significant difference of prediction accuracies as well as the significant difference of preference matching rates (Table 2 to Table 4).
2. Are preferences consistent when the attributes of product appearance are evaluated all together (conjoint analysis) compared with evaluated separately (directly stated)?

No. The preference model reveals the appearance preference for solar panel when all the attributes are presented together within an integrated image. The directly stated preference represents the appearance preference considering the attributes independently. In this study, the preference for color is pretty consistent. However the preference for shape, pattern and frame are not consistent when evaluated in different ways. Table 6 shows the changing of most preferred attributes revealed in these two ways. However which one of these two preference-revealing methods is better is open to question and is out of the scope of this study.

3. If the preference for product appearance is not consistent, then what are the main factors that influence the preference?

In this study the context in which the product is presented plays an important role in bias the appearance preference. This can be seen from respondents' choices of color in part $\mathrm{V}$ of the survey (Table 5), when they are asked to choose the best combination of the attributes to create solar panels to match the roof of house given. It appears that, a majority of respondents consider the consistency of the color of solar panel and the color of roof represents a better looking. Thus the preference for the appearance of the solar panel is not only a question about the product itself, but also a question about what the environment in which the product is used looks like.

Further we could argue that, the closer the visual representation looks to the final product and the closer the testing environment looks to the real using context, the more realistic the revealed appearance preference will be. Which product looks better can be a subtle question to ask, since insignificant factors such as the intensity of lighting could change people's opinion. Thus, when revealing consumers' preference for product appearance, it is important to make the visual representation look vivid, not only the product itself,

Table 6: Changing of 'Most Preferred' attributes from conjoint analysis revealed to directly stated

\begin{tabular}{|c|c|c|c|c|c|c|}
\hline \multirow{2}{*}{\multicolumn{2}{|c|}{ Color }} & \multicolumn{4}{|c|}{ Directly stated } & \multirow{3}{*}{$\frac{\text { Sum }}{102}$} \\
\hline & & Black & Blue & Red & Green & \\
\hline \multirow{5}{*}{$\begin{array}{l}\text { Conjoint } \\
\underline{\text { Anlaysis }}\end{array}$} & Black & 95 & 5 & 1 & 1 & \\
\hline & Blue & 9 & 40 & 1 & 2 & 52 \\
\hline & Red & 2 & 2 & 4 & 1 & 9 \\
\hline & Green & 11 & 8 & 2 & 10 & 31 \\
\hline & Sum & 117 & 55 & 8 & 14 & 194 \\
\hline \multirow{2}{*}{\multicolumn{2}{|c|}{ Pattern }} & \multicolumn{4}{|c|}{ Directly stated } & \\
\hline & & None & & wo & Three & Sum \\
\hline \multirow{4}{*}{$\begin{array}{l}\text { Conjoint } \\
\underline{\text { Anlaysis }}\end{array}$} & None & 62 & & 36 & 15 & 113 \\
\hline & Two & 22 & & 18 & 8 & 48 \\
\hline & Three & 8 & & 12 & 13 & 33 \\
\hline & Sum & 92 & & 56 & 36 & 194 \\
\hline
\end{tabular}

\begin{tabular}{|c|c|ccc|c|}
\hline \multicolumn{2}{|c|}{ Shape } & \multicolumn{3}{c|}{ Directly stated } & \\
\hline \multirow{3}{*}{ Conjoint } & Big C & Small C & Square & Sum \\
\hline \multirow{2}{*}{ Anlaysis } & Big C & $\mathbf{2 9}$ & 38 & 22 & 89 \\
\cline { 2 - 6 } & Small C & 10 & $\mathbf{3 4}$ & 29 & 73 \\
\cline { 2 - 6 } & Square & 0 & 9 & $\mathbf{2 3}$ & 32 \\
\cline { 2 - 6 } & Sum & 39 & 81 & 74 & 194 \\
\hline
\end{tabular}

\begin{tabular}{|c|c|ccc|c|}
\hline \multicolumn{2}{|c|}{ Frame } & \multicolumn{3}{c|}{ Directly stated } & \\
\hline \multirow{3}{*}{ Conjoint } & Silver & Black & None & Sum \\
\hline Anlaysis & Black & 14 & 20 & 7 & 41 \\
& None & 12 & $\mathbf{5 0}$ & 24 & 86 \\
\cline { 2 - 6 } & Sum & 40 & 109 & 45 & 194 \\
\hline
\end{tabular}


but also the using context. In contrast, if the visual representation of the product is different from what it really looks like, designers may receive biased information about customer preference, and therefore make wrong decision on product design.

The preference inconsistency could also be explained from a cognitive perspective, since aesthetic experience can also be regarded as a cognitive activity [27]. When revealing preference using conjoint analysis, participants are shown a combination of the attributes as a whole product. Thus they can have a visual impression of what the product looks like with all the attributes. When deciding which solar panel looks better, they actually don't have to distinguish the individual attributes, but make decisions based on the general impression received from the images. However, when revealing preferences using direct statement, a list of attribute levels is showed and participants need to consider them independently. How a product looks with all the attributes is largely dependent on the participants' imagination. The difference between the ways customers evaluate the product could be the reason why preference for its appearance is changed.

\section{CONCLUSION}

This paper investigates the inconsistency of consumers' preference for the appearance of technology product with a case study of solar panels. In this work, four main attributes that influence the appearance of a residential solar panel are identified. Visual choice based conjoint analysis is used as a main method to reveal the preference model.

Inconsistencies of product appearance preference arise when the style of images presenting the product changed from non-contextualized images of solar panel with a blank background to contextualized images of solar panel within a realistic context. The context in which the product is presented is believed to be the main factor that bias consumers' preference. It is not necessarily true that one type of representation is inherently better than another, but if the goal is to increase solar panel adoption, the suggestion of this result is that panels that are designed to match home roofs are strongly preferred, regardless of the standalone styling of the panel.

The result of the study has implications for the way stakeholders and companies represent their products to users and the broader world. The existence of preference inconsistencies suggests designers to be cautious when studying customers' preference for product appearance. And the reasons behind the existence of inconsistencies give designers insights into how to address the "real" customer preference that will lead to higher satisfaction after the design of product completed.

\section{FUTURE WORK}

The broader context of this work is in the way we formulate design requirements for products. This paper focuses specifically on gathering user needs and desires, and future work should consider how to formally link this type of feedback on designs to design requirements.

In this study, the existence of preference inconsistencies to product appearance is demonstrated by significant statistical data. However, the reasons behind them are more of a qualitative analysis than quantitative experimental study. Thus designing an experiment to further proving the arguments made in this paper is important.

In this study, the appearance preference is studied on an individual level. However it will be interesting to further explore the preference on a group level using part-worth utility model.

Last but not the least, only one kind of technology product is studied in this paper. Expanding this study to other technology products, even to other consumer products with more complicated constitution of aesthetic, should give out results with more general value.

\section{ACKNOWLEDGEMENT}

The authors would like to thank the King Fahd University of Petroleum and Minerals in Dhahran, Saudi Arabia, for funding the research reported in this paper through the Center for Clean Water and Clean Energy at MIT and KFUPM.

\section{REFERENCE}

[1] Creusen, M. E. H. and Schoormans, J. P. L. (2005), The Different Roles of Product Appearance in Consumer Choice. Journal of Product Innovation Management, 22: 63-81.

[2] Faste, R. (1987). Perceiving Needs. SAE Technical Paper 871534, Society of Automotive Engineers.

[3] Tovares, Noah, and Peter Boatwright. 2013. "Capturing Consumer Preference Through Experiential Conjoint Analysis." ASME 2013 International Design Engineering Technical Conferences and Computers and Information in Engineering Conference. American Society of Mechanical Engineers.

[4] Orsborn, Seth, Jonathan Cagan, and Peter Boatwright. 2009. "Quantifying Aesthetic Form Preference in a Utility Function.” Journal of Mechanical Design 131 (6): 061001.

[5] MacDonald, Erin F., Richard Gonzalez, and Panos Y. Papalambros. 2009. "Preference Inconsistency in Multidisciplinary Design Decision Making.” Journal of Mechanical Design 131 (3): 031009

[6] Kulok, M. and K. Lewis (2005). "Preference Consistency in Multiattribute Decision Making." ASME Conference Proceedings 2005(4742Xa): 291-300. 
[7] Bamossy, Gary, Scammon, Debra L. and Johnston, Marilyn (1983). A Preliminary Investigation of the Reliability and Validity of an Aesthetic Judgment Test. In: Advances in Consumer Research. Richard P.Bagozzi and Alice M.Tybout (eds.). Ann Arbor, MI: Association for Consumer Research, 685-690.

[8] Reid, T., MacDonald, E., and Du, P., 2013, "Impact of Product Design Representation on Customer Judgment," Journal of Mechanical Design, Vol. 135, No. 9, 091008.

[9] Robert W. Veryzer, Jr. (1995). The Place of Product Design and Aesthetics in Consumer Research, in NA Advances in Consumer Research Volume 22, eds. Frank R. Kardes and Mita Sujan, Provo, UT : Association for Consumer Research, Pages: 641-645.

[10] Bloch, P. H. (1995). Seeking the Ideal Form: Product Design and Consumer Response. Journal of Marketing, 59(3), 16.

[11] Crilly, N., Moultrie, J., \& Clarkson, P. J. (2004). Seeing things: consumer response to the visual domain in product design. Design Studies, 25(6), 547-577.

[12] Orsborn, Seth, et al. "Creating cross-over vehicles: Defining and combining vehicle classes using shape grammars." AIEDAM-Artificial Intelligence Engineering Design Analysis and Manufacturing 20.3 (2006): 217246.

[13] Nathan-roberts, D. (2012). Using Interactive Genetic Algorithms to Support Aesthetic Ergonomic Design. Diss. The University of Michigan, 2012

[14] Macomber, B., \& Yang, M. (2011). The Role of Sketch Finish and Style in User Responses to Early Stage Design Concepts. DETC2010-48714. Proceedings of the 2011 ASME Intl Design Engineering Technical Conferences, Aug 28-31, Washington, DC

[15] Walker, M., L. Takayama and J. A. Landay (2002). High-Fidelity or Low-Fidelity, Paper or Computer Choosing Attributes When Testing Web Prototypes. Human Factors and Ergonomics Society Annual Meeting, Human Factors and Ergonomics Society.

[16] Chen, T. Honda, and M. C. Yang, (2013) "Approaches for Identifying Consumer Preferences for the Design of Technology Products: A Case Study of Residential Solar Panels," ASME Journal of Mechanical Engineering Design, 135(6), 061007
[17] Paul E. Green, (1974). "On the Design of Choice Experiments Involving Multifactor Alternatives”, Journal of Consumer Research, Vol. 1, No. 2, pp. 61-68

[18] Kuhfeld W.F., 2010, "Conjoint Analysis", SAS Technical Papers, MR-2010H, pp. 681-801

[19] Aizaki, H., \& Nishimura, K. (2008). Design and Analysis of Choice Experiments Using R: A Brief Introduction. Agricultural Information Research, 17(2), 86-94.

[20] Kuhfeld W.F., 2010, "Discrete Choice”, SAS Technical Papers, MR-2010F, pp. 285-663

[21] Kelly, J., and Papalambros, P.Y., 2007. "Use of shape preference information in product design", Proc. ICED 2007, Paris, France, Aug. 28 - 31, 2007. Paper No. ICED07-867

[22] Swamy, S., Orsborn, S., Michalek, J., and Cagan, J., 2007, "Measurement of headlight preference using choice based conjoint analysis", Proc. IDETC/CIE, Sept. 4-7, 2007, Las Vegas, Nevada. Paper No. DETC200735409

[23] Reid, Tahira, Richard Gonzalez, and Panos Papalambros. "A methodology for quantifying the perceived environmental friendliness of vehicle silhouettes in engineering design." Proceedings of the ASME 2009 International Design Engineering Technical Conferences \& Computers and Information in Engineering Conference. 2009.

[24] Sylcott, Brian, Jonathan Cagan, and Golnaz Tabibnia. "Understanding Consumer Tradeoffs Between Form and Function Through Metaconjoint and Cognitive Neuroscience Analyses." Journal of Mechanical Design 135.10 (2013): 101002.

[25] CSI, 2011. California solar initative: Current CSI data. http://www.californiasolarstatistics.org/current data files/.

[26] Hey, J. D. (1998). Do Rational People Make Mistakes. Game Theory, Experience, Rationality, 55-66.

[27] Consoli, Gianluca. "A Cognitive Theory of the Aesthetic Experience." Contemporary Aesthetics 10 (2012). 


\section{APPENDIX}

\begin{tabular}{|c|c|c|c|c|c|}
\hline Attributes & Num. of Levels & Level 1 & Level 2 & Level 3 & Level 4 \\
\hline Color & 4 & & & & \\
\hline Shape & 3 & & & \\
Pattern & 3 & & & \\
\hline Frame & & & & \\
\hline
\end{tabular}

Table: Images of the levels of attributes

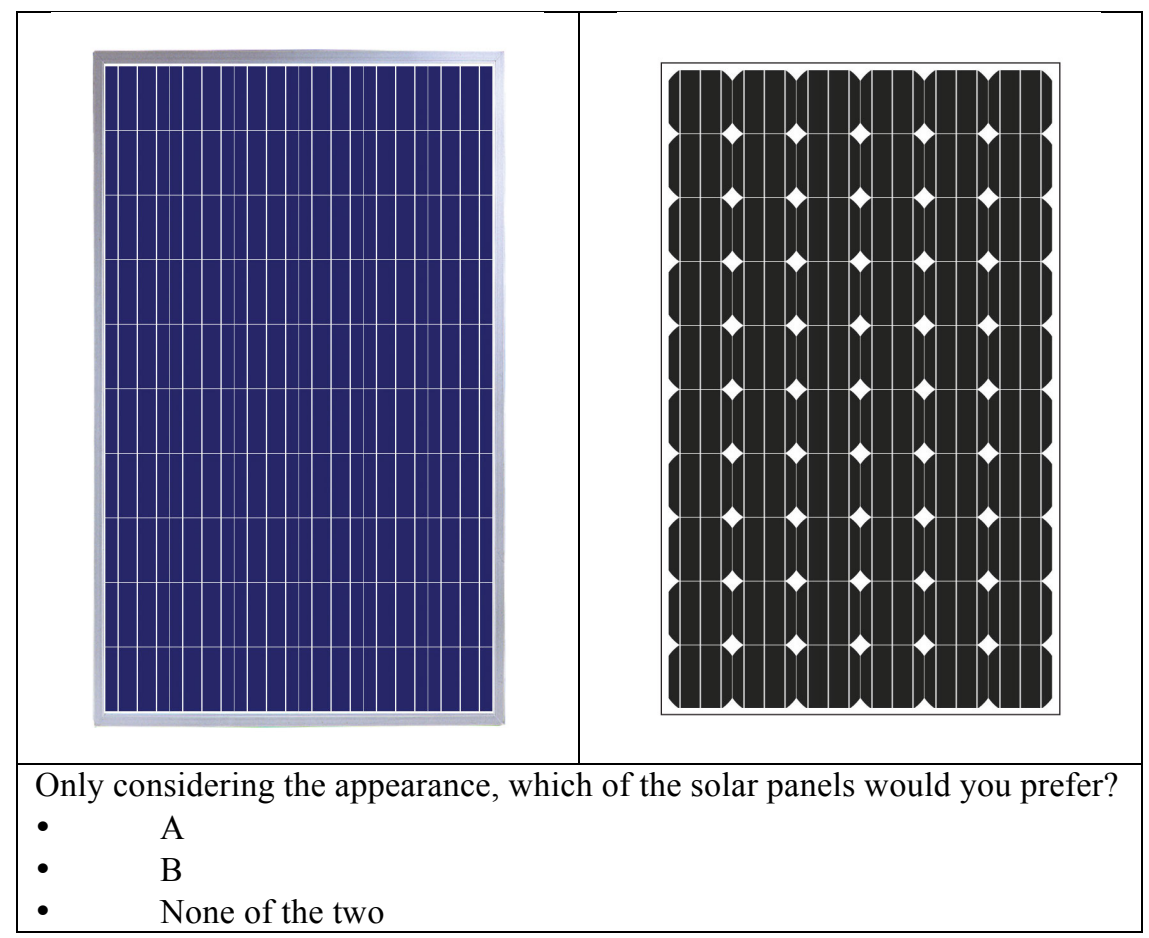

Figure: Question example of survey Part II 


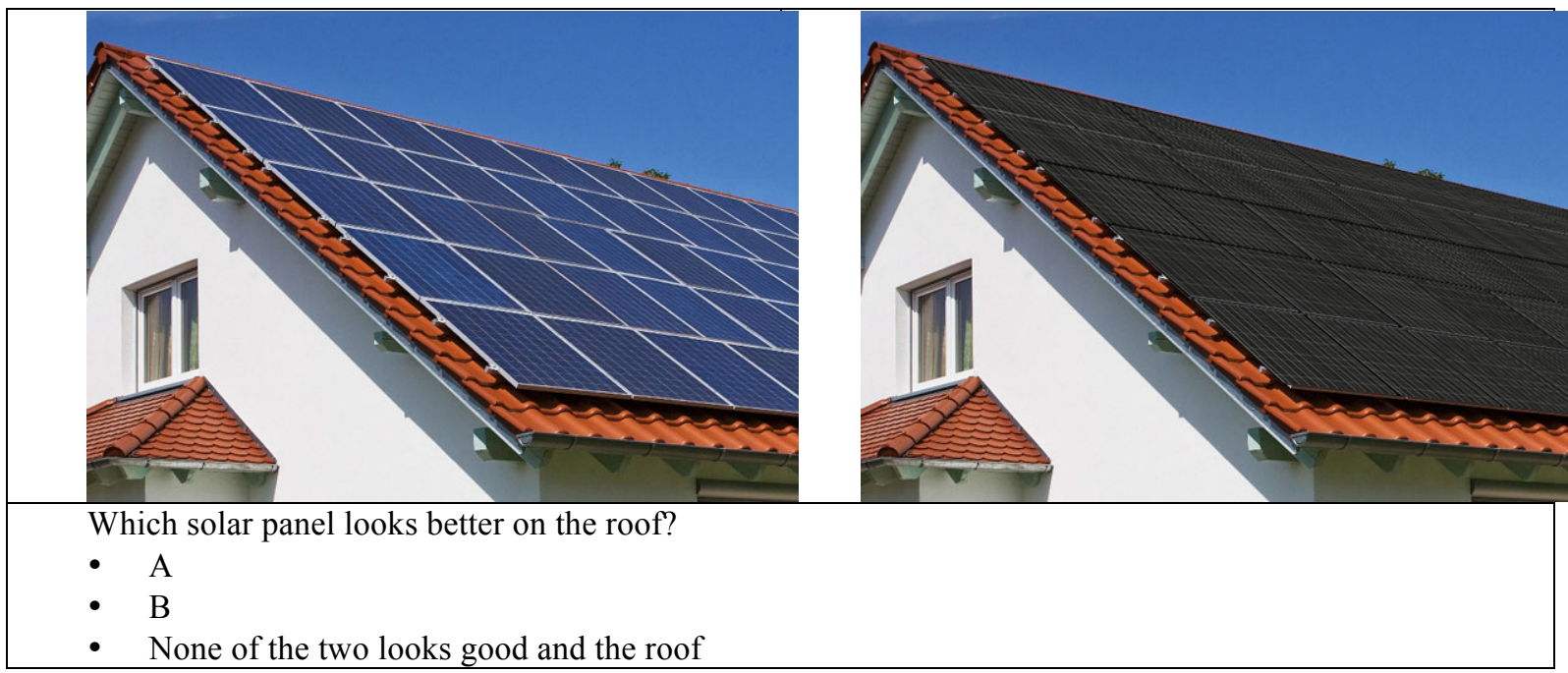

Figure: Question example of survey Part IV

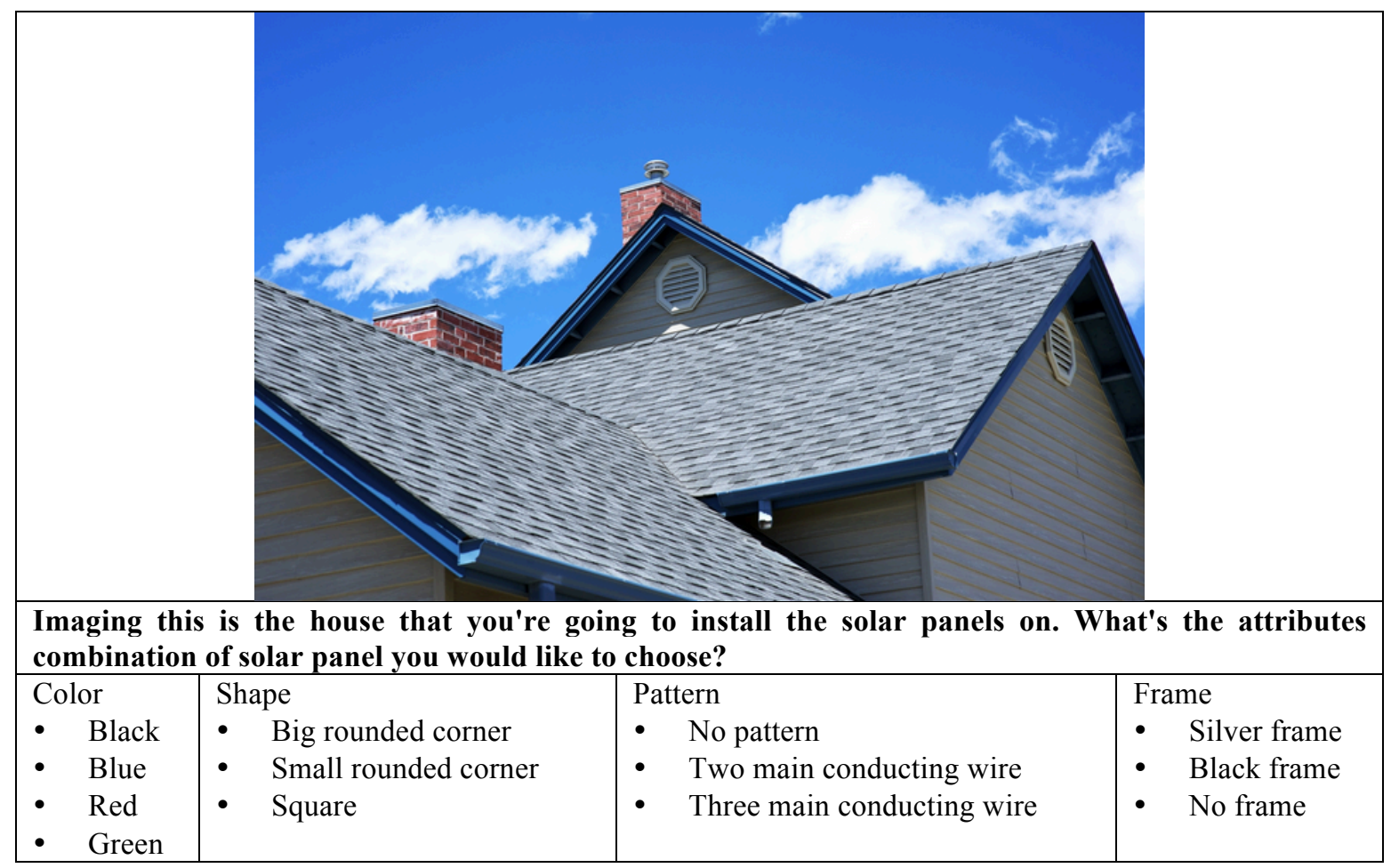

Figure: Question example of survey Part V 